\title{
JOGA PEDRA NA GENI: UMA DISCUSSÃO PARA ALÉM DOS TERRITÓRIOS URBANOS DE SOCIABILIDADES GAYS NA CIDADE DE SALVADOR-BA
}

\section{Play stone in Geni: A discussion beyond the urban territories of gay sociabilities in the city of Salvador-BA}

\section{Juega piedra en la Geni: Uma discusión para más allá de los territorios urbanos de socialidades gays en la ciudad de Salvador-BA}

Célio Silva Meira ${ }^{1}$ http://orcid.org/0000-0003-2000-7587

Lucas Aguiar Tomaz Ferreira $^{2}$ http://orcid.org/0000-0002-0302-7079

\footnotetext{
${ }^{1}$ Doutor em Planejamento Territorial e Desenvolvimento Social pela Universidade Católica do Salvador - UCSal, Bahia - Brasil, membro do grupo de pesquisa DSN (Desenvolvimento, Sociedade e Natureza). E-mail: celiomeira2014@ gmail.com

${ }^{2}$ Graduando em Geografia pela Universidade Estadual do Sudoeste da Bahia - UESB, Bahia - Brasil. E-mail: lucasaguiar04@hotmail.com
}

\section{Resumo}

$\mathrm{O}$ artigo, aqui apresentado, objetivou discutir sobre os territórios de identidades relacionados às minorias sexuais dentro dos espaços urbanos. Tomamos como referência o debate sobre território e o percurso histórico da luta pela visibilidade das manifestações de membros da comunidade de Lésbicas, Gays, Bissexuais, Travestis, Transexuais, Transgêneros, Queer e Intersexis-LGBTQI+. Fazendo uma correlação da música Geni e o Zepelim de Chico Buarque com as violências que esses sujeitos sociais sofrem, e o porquê dos mesmos procurem espaços específicos de socialização. A partir desta perspectiva, trouxemos algumas discussões do campo empírico aqui analisado, a cidade de Salvador Bahia e seus territórios de "liberdade" para as minorias que expressam orientações sexuais diferentes do padrão heteronormativo.

Palavras-chave: Territórios Urbanos. Identidades. Sociabilidades Gays.

\begin{abstract}
The article, presented here, aimed to discuss the territories of identities related to sexual minorities within urban spaces. We take as a reference the debate on territory and the historical path of the struggle for the visibility of the manifestations of members of the community of Lesbian, Gay, Bisexual, Transvestite, Transsexual, Transgender, Queer and Intersexis-LGBTQI +. Making a correlation of the Geni music and the Zeppelin of Chico Buarque with the violence that these social subjects suffer, and why they seek specific spaces of socialization. From this perspective, we have brought some discussions of the empirical field analyzed here, the city of Salvador - Bahia and its territories of "freedom" for minorities that express sexual orientations different from the heteronormative pattern.
\end{abstract}

Keywords: Urban Territories. Identities. Gay Sociabilities. 


\section{Resumen}

El artículo, aquí presentado, objetivó discutir sobre los territorios de identidades relacionados a las minorías sexuales dentro de los espacios urbanos. Tomamos como referencia el debate sobre territorio y el recorrido histórico de la lucha por la visibilidad de las manifestaciones de miembros de la comunidad de Lesbianas, Gays, Bisexuales, Travestis, Transexuales, Transgéneros, Queer e IntersexisLGBTQI +. Haciendo una correlación de la música Geni y el Zepelín de Chico Buarque con las violencias que esos sujetos sociales sufren, y el porqué de los mismos busquen espacios específicos de socialización. A partir de esta perspectiva, trajimos algunas discusiones del campo empírico aquí analizado, la ciudad de Salvador - Bahía y sus territorios de "libertad" para las minorías que expresan orientaciones sexuales diferentes del patrón heteronormativo.

Palabras clave: Territorios Urbanos. Identidades. Sociabilidades Gays.

Recebido em: 27/10/2018

Aceito para publicação em: 20/12/2018

\section{Introdução}

Este texto tem o intuito de reverberar acerca dos territórios urbanos destinados às minorias LGBTQI+ ${ }^{3}$, sigla esta que nós nos classificamos perante a cultura heteronormativa, cultura que foi vista como a única verdadeira, ideal e legitimada por muito tempo pelo senso comum, tudo que não se enquadrava nela era desprezível, subalternizado, ignóbil.

Outrossim, para a composição deste artigo, tomamos como alusão a letra da música Geni e o Zepelim composta e cantada por Chico Buarque de Holanda em 1978. Muitos usam essa música para diversos fins, neste artigo, vem enquanto uma reflexão sobre a condição de abjeção, assujeitamento das quais as minorias a que trata este texto, são vitimadas em nossa sociedade.

A letra descreve, em versos, a longa história que define o episódio ocorrido com Geni, uma travesti - segundo representado na "Ópera do Malandro" e expresso em partes da letra -, que era hostilizada na cidade. Diante de uma ameaça de ataque de um Zepelim o comandante se encanta com os dotes de Geni, que acaba sendo provisoriamente tratada de um modo diferenciado pelos seus detratores. Passada a ameaça, ela retorna ao seu dia-a-dia normal, no qual as pessoas a ofendiam e excluíam, revelando o caráter pseudomoralista e hipócrita da sociedade. A música mostra o grande preconceito ainda fortemente presente em relação ás travestis, aos gays, ás lésbicas, etc. o que acaba levando essas pessoas a procurarem espaços, guetos de sociabilidades dentro dos espaços urbanos.

As discussões teóricas acerca do sistema de gênero/sexo/sexualidade deram nas últimas décadas, em especial a partir dos anos 2000, um salto representativo em produção

${ }^{3}$ Lésbicas, Gays, Bissexuais, Travestis, Transexuais, Transgêneros, Queer e Intersexis. 
acadêmica no campo das Ciências Sociais. Tal fato tem repercutido de modo positivo nos lugares ocupados por estes sujeitos. Ao passearmos, por exemplo, pelas obras de Stuart Hall (2003), Paul B. Preciado ( 2017), Javier Sáez\& Sejo Carrascosa ( 2016), Richard Miskolci (2016), Judith Butler (2017), Michel Foucault (1988), Leandro Colling (2013), dente outros pensadores, faz lembrar a importância do desenvolvimento dos Estudos Culturais para trazer à tona questões sociais até então invisibilizadas pelo conhecimento acadêmico, em que cada vez mais temos a participação de minorias na construção de saberes, apesar de vivermos tempos sombrios ultimamente, onde toda essa produção se encontra ameaçada por ideologias racistas, fascistas e ditadoras.

Para a realização desta pesquisa, utilizamos a Etnografia como método de pesquisa, segundo Angrosino (2009, p. 30), “A etnografia é a arte e a ciência de descrever um grupo humano, suas instituições, seus comportamentos interpessoais, suas produções materiais e suas crenças". O método etnográfico difere de outros modos de fazer pesquisa, na medida em que ele:

Baseia-se na pesquisa de campo (conduzido no local onde as pessoas vivem e não em laboratório onde o pesquisador controla os elementos do comportamento a ser medido e observado). É personalizado (conduzido por pesquisadores que, no dia a dia, estão face a face com as pessoas que estão estudando e que, assim, são tanto participantes quanto observadores das vidas em estudo). É multifatorial (conduzido pelo uso de duas ou mais técnicas de coleta de dados - os quais podem ser de natureza qualitativa ou quantitativa). Requer um compromisso de longo prazo, ou seja, é conduzido por pesquisadores que pretendem interagir com as pessoas que eles estão estudando durante um longo período de tempo (embora o tempo exato possa variar, digamos, de algumas semanas a um ano ou mais). $E$ indutivo (conduzido de modo a usar um acúmulo descritivo de detalhe para construir modelos gerais ou teorias explicativas, e não para testar hipóteses derivadas de teorias ou modelos existentes). $E$ dialógico (conduzidos por pesquisadores cujas conclusões e interpretações podem ser discutidas pelos informantes na medida em que elas vão se formando). É holístico (conduzido para revelar o retrato mais completo possível do grupo em estudo) (ANGROSINO, 2009, p. 31).

Para buscar os dados de campo da pesquisa, fizemos uso da entrevista, uma ferramenta importante que proporcionou o levantamento de várias informações relativas às populações LGBTQI+ pesquisadas a partir de uma análise das informações contidas nas falas das pessoas observadas e entrevistadas. Para tanto, foi escolhida a entrevista semiestruturada, que aliou a formulação de questões prévias, com temas que surgiram no decorrer da discussão. Realizamos uma média de 10 entrevistas em diferentes espaços de sociabilidades gays na cidade de Salvador. 
A entrevista foi iniciada conforme orienta Montenegro (2013), com uma conversa de esclarecimento com o entrevistado, "para que este entenda, por que, para que e para quem ele está relatando suas histórias de vida". Para preservar os nomes dos entrevistados, os mesmos estão identificados por meio de pseudônimos.

Os roteiros das entrevistas foram elaborados anteriormente e com questões relativas aos níveis de conhecimentos e especificidades dos entrevistados dos espaços de sociabilidades gays da cidade de Salvador-Bahia, e realizadas entre os meses de Março a Junho de 2018. As entrevistas foram gravadas e depois transcritas e usadas como depoimentos ao longo da construção do texto. Os recursos metodológicos usados não seguiram regras rígidas, por se tratar de uma pesquisa qualitativa, em que sua "diversidade e flexibilidade" não pediram regras fixas, sem, contudo, abrir mão do rigor metodológico.

\section{Território e seus múltiplos enfoques}

O debate acerca do conceito de território e, consequentemente, de territorialidade não constitui uma novidade para as discussões no campo da ciência geográfica, tendo sua gênese na Geografia Política Clássica. Embora haja polissemia que envolva sua definição, tem ensejado, nos últimos anos, debates profícuos no seio de diversas áreas das Ciências Humanas.

Por ter ficado durante muitos anos, restrito ao âmbito da Geografia, criou-se uma ideia equivocada de que este tema era exclusividade desta ciência, embora vale ressaltar que a origem do termo território e o seu emprego nas ciências humanas não advém dos estudos geográficos (HAESBAERT, 2004; SAQUET, 2010), sendo sua utilização originária no campo das ciências da natureza, em especial, da Biologia e da Zoologia, a partir dos estudos ligados à Etologia.

É com os estudos do alemão Friedrich Ratzel, um dos precursores da abordagem do termo território, especialmente no campo da epistemologia geográfica, associando-o à ideia de "espaço vital", enquanto elemento fundamental no processo de "desenvolvimento" das Nações no contexto do expansionismo imperialista da Europa do final do século XIX, que acaba levando a um arrefecimento das discussões sobre o tema do território; este, refere-se ao território como substrato (palco) para a efetivação da vida humana, sinônimo de solo/terra e outras condições naturais, fundamentais a todos os povos, selvagens e civilizados sob o domínio do Estado. 
Na visão de Ratzel (1990), é no elo indissociável entre uma dimensão físico-natural (solo e seus recursos) e uma dimensão política do espaço (quase confunde com o estatal) que o território se define. Dizia ele: "É fácil convencer-se de que do mesmo modo como não se pode considerar mesmo o Estado mais simples sem o seu território, assim também a sociedade mais simples só pode ser concebida junto com o território que lhe pretence"! (RATZEL, 1990, p. 73).

E continua...

Os organismos que fazem parte da tribo, da comuna, da família, só podem ser concebidos junto com seu território. Sem isso não é possível o seu desenvolvimento, assim como sem território não se poderia compreender o incremento da potência e da solidez do Estado (RATZEL, 1990, p. 74).

Com isso, pode-se dizer que o conceito de território defendido por Ratzel tem como cerne a base físico-natural do Estado-Nação. Trata-se de um território que, com sua população, suas fronteiras, seus recursos naturais etc., constituem-se no suporte fundamental para o desenvolvimento da Nação e o fortalecimento de um dado Estado.

Esse "desenvolvimento", na perspectiva ratzeliana, depende do controle, da manutenção e da conquista de novos territórios, o que ele denomina de "espaços vitais". $\mathrm{Na}$ visão de Ratzel, o controle da posse de novos territórios um dos fatores fundamentais na constituição do Estado:

A sociedade que consideramos, seja grande ou pequena, desejará manter, sobretudo a posse do seu território sobre o qual e graças ao qual ela vive. Quando essa sociedade se organiza com esse objetivo, ela se transforma em Estado (RATZEL, 1990, p. 76).

Aqui, ressaltamos que as observações/estudos efetivados por Ratzel fundamentavamse em pressupostos filosóficos e metodológicos tipicamente característicos à sua época (que tinha como matriz teórica o pensamento Positivista defendido por estudiosos do porte de Emile Durkheim, dentre outros). Mesmo assim, conforme argumenta Moraes (1998, p. 56), já representava uma visão geográfica avançada para sua época, na medida em que compreendia o espaço como um "lugar de equilíbrio dinâmico entre a população de uma dada sociedade e os recursos disponíveis para suprir suas necessidades”, definindo, assim, suas condições de progredir e expandir-se. Visão esta que, aliás, esteve a serviço de um discurso de caráter, eminentemente, expansionista à época. 
Para Saquet (2010), é somente a partir das décadas de 1960-70 do século passado que são alavancados novos estudos sobre a temática do território. Segundo o supracitado autor, este período histórico é extremamente fértil para a produção acadêmica do pensamento geográfico de outras ciências, pois, este está em pleno processo de renovação e de rompimento com os ditames teórico-metodológicos do pensamento positivista do final século XIX. Agora, sob uma nova ótica, a influência da corrente de pensamento pautada no materialismo histórico dialético e da corrente fenomenológica, juntas traduzem perspectivas múltiplas de análise do território. "A partir de então é que o conceito de território renasce de forma renovada e sistemática, contemplando a noção de dinamismo, contradições, relações de poder, identidades, redes de circulação e comunicação, etc.” (SAQUET, 2010, p. 44).

Haesbaert complementa afirmando:

Do conceito de território se funda agora em novas e atualizadas leituras encontrando-se desde territórios como "abrigo" até territórios vinculados ao ciberespaço, em que o controle é feito pelos meios informacionais mais sofisticados [...]. Trata-se de um desdobramento a partir de sua vinculação em uma perspectiva mais sistematizada da concepção de 'múltiplos territórios' ou de 'multiterritorialidade' conjugando uma multiplicidade ou diversidade territorial de justaposição ou convivência, lado a lado, de tipos territoriais distintos e complexos (HAESBAERT, 2004, p. 69).

O fato mais interessante disso tudo é que o debate sobre território foi retomado com a devida importância a que merece e suas qualificações também são decorrentes dessa importância. Uma delas, sem sombra de dúvida, foi a questão inerente à territorialidade que, dentre outros, "designa a qualidade que o território ganha de acordo com sua utilização ou apreensão pelo ser humano" (SPOSITO, 2009, p. 11). Esse caráter tem sido amplamente discutido em diferentes áreas das ciências humanas com destaque para a Geografia.

É impar destacarmos, aqui, as contribuições de Claude Raffestin (1993) no campo da abordagem territorial. Neste, verifica-se uma concepção múltipla de território e territorialidade. Apesar de fazer uma análise de caráter mais econômica e política do território, este, reconhece a complementaridade entre as dimensões da economia, da política e da cultura. Para este, o espaço é a base para a formulação/concretização do território, ou seja, o espaço existe antes do território, ele é o "substrato" para a construção deste último.

Espaço e território não são termos equivalentes [...]. É essencial compreender bem que o espaço é anterior ao território. O território se forma a partir do espaço, é o resultado de uma ação conduzida por um ator 
sintomático (ator que realiza um programa) em qualquer nível (RAFFESTIN, 1993, p. 143).

E continua...

Do Estado ao indivíduo passando por todas as organizações pequenas ou grandes, encontramos atores sintagmáticos que 'produzem' territórios [...], em graus diversos, em momentos diferentes e em lugares variados, somos todos atores sintagmáticos que produzem territórios (RAFFESTIN, 1993, p. 152).

O território em Raffestin é concebido por um conjunto de relações que o indivíduo ou grupos destes - os agentes sociais - mantêm entre si e com a natureza. Destarte, para este autor o território não poderia ser mais nada senão produto dos atores sociais. São eles que constroem o território, partindo da realidade inicial dada, que é o espaço. Afinal, para ele, o território se forma a partir do espaço. "Ao se apropriar de um espaço concreto ou abstratamente, o ator territorializa este" (RAFFESTIN, 1993, p. 143).

Souza (2013) nos afirma que a apropriação territorial é eminentemente marcada por relações de poder, enquanto aspecto fundamental para a compreensão do território, sendo exercido por pessoas ou grupos, sem o qual não se define o território. "O espaço territorializado é, em última análise, um instrumento de exercício de poder" (SOUZA, 2013, p. 87). E complementa afirmando que os "territórios não são matéria tangível, palpável, mas sim, campo de força [...] e que o espaço social é multifacetado, e é sensato aceitar que o território nada mais é que uma de suas facetas" (SOUZA, 2013, p. 99-100), e o autor diz que:

Sem dúvida sempre que houve homens em interação com o espaço, primeiramente transformando a natureza (espaço natural) através do trabalho, e depois criando continuamente valor ao modificar e retrabalhar o espaço social estar-se-á também diante de um território e não só de um espaço econômico; [...] é inconcebível que um espaço que tenha sido alvo de valorização pelo trabalho possa deixar de estar territorializado por alguém (SOUZA, 2001, p. 96).

Sem querer adentrar no mérito da questão, pois não é o objetivo deste trabalho, é pertinente frisar que, não poucas vezes, o conceito de território tem sido eventualmente confundido com o de espaço.

A essência desta confusão reside exatamente no fato de que muitos autores, por partirem do pressuposto e que o território é efetivado a partir da apropriação social do espaço - compreensão corretíssima - consideram-no 
apenas como sinônimo de chão, de propriedade, de área, de limite administrativo (EDUARDO, 2006, p. 55).

Há diferenciações entre espaço e território, isto é, eles não são sinônimos, como nos mostra Haesbaert e Limonad (2007, p. 42): “O território é uma construção histórica e, portanto, social, a partir das relações de poder (concreto e simbólico) que envolvem, concomitantemente, sociedade e espaço geográfico - que também é sempre de alguma forma natureza.”.

A esse respeito, vale também trazer as contribuições de Saquet (2010), onde faz questão de lembrar que:

O espaço corresponde ao ambiente natural e ao ambiente organizado socialmente, enquanto que o território é produto de ações históricas que se concretizam em momentos distintos e sobrepostos, gerando diferentes paisagens, logo, é fruto da dinâmica sócio espacial (SAQUET, 2010, p. 82).

Neste sentido, considera-se que o território pode ser entendido como uma forma de apropriação social do ambiente; é o ambiente sendo construído, em que há múltiplas variáveis e relações recíprocas e unitárias. Porém, vale ressaltar aqui, que espaço e território não estão separados, um está no outro, não são conceitos estanques e sim imbricados. "O espaço é indispensável para a apropriação e reprodução do território" (SAQUET, 2010, p. 83). Também já propugnara Haesbaert (2009), estes jamais poderão ser fragmentados, já que sem espaço não há territórios, especialmente quando se reconhece a trilogia tempo-espaçoterritório como elementos indissociáveis do real.

Haesbaert (2004) volta a complementar que o território não está desvinculado de sua origem epistemológica - a posse de terra - mas passa a ser concebido e dotado também de uma "carga culturalista", isto é, diz respeito tanto ao poder num sentido mais concreto da palavra, de dominação mesmo, quanto num sentido mais simbólico, de apropriação, de enraizamento. "A apropriação do espaço por um grupo social passa a não ser mais compreendida sem o seu território, base de sua história, cultura e sustentação" (HAESBAERT, 2004, p. 100).

O supracitado autor faz também uma distinção entre o que ele denomina de "território unifuncional" e "território espaço-tempo-vivido". O primeiro está relacionado à lógica capitalista hegemônica, ou seja, a figura do Estado, que não admite multiplicidade/sobreposições de jurisdições e/ou territorialidades. Já o segundo, aparece como resultado de processos diversos e complexos produzido nas tramas materiais e imateriais do cotidiano social, ou seja, na vivência e na identidade das pessoas (HAESBAERT; 
LIMONAD, 2007). Neste sentido, o território compreenderia uma apropriação mais simbólico-identitária, determinados por ações de certos grupos sociais sobre o espaço onde se reproduzem socialmente. Assim, devemos primeiramente distinguir os territórios de acordo com aqueles que os constroem e/ou controlam, sejam eles indivíduos, grupos sociais, Estado, empresas, instituições etc. Além disso, faz-se necessário reconhecer que "os objetivos do controle social através de sua territorialização variam conforme a sociedade ou cultura, o grupo e, muitas vezes, com o próprio indivíduo" (HAESBAERT; LIMONAD, 2007, p. 22).

Souza (2013) afirma que territórios existem e são construídos (e desconstruídos) dentro de escalas temporais das mais diferentes e que podem ter um caráter permanente, mas também podem ter uma existência periódica ou cíclica. Saquet, assim entende que:

O território significa heterogeneidade e traços comuns; apropriação e dominação historicamente condicionadas; é produto e condição histórica e trans-escalar; com múltiplas variáveis, determinações, relações e unidade. É espaço de moradia, de produção, de serviços, de mobilidade, de desorganização, de arte, de sonhos, enfim, de vida (objetiva e subjetivamente). O território é processual e relaciona, (i)material, com diversidade e unidade, concomitantemente (SAQUET, 2010, p. 83).

Conforme também observou Fernandes (2009), território é um todo e que este todo é parte integrante da realidade.

Quando compreendemos o território como um todo, estamos entendendo sua multidimensionalidade. Isso significa que ao analisar os territórios por meio de uma ou mais dimensões, é somente uma opção, o que não implica em desconsiderar as outras dimensões. O princípio da multidimensionalidade nos ajuda a compreender melhor o da totalidade, já que são as dimensões que a compõem (FERNANDES, 2009, p. 2002).

As dimensões referidas por este autor são formadas pelas condições construídas/arquitetadas pelos sujeitos em suas práticas sociais cotidianas na relação com a natureza e entre si. Nas múltiplas dimensões do território, afirma Saquet (2007), é que são produzidas relações sociais, econômicas, políticas, ambientais e, sobretudo, culturais. Cada combinação específica de cada relação espaço-tempo é produto, acompanha e condiciona os fenômenos e processos territoriais (SAQUET, 2007).

Assim sendo, Saquet (2010, p. 173) afirma que "os homens têm centralidades na formação de cada território, cristalizando relações de influência, efetivas, simbólicas, conflitos e identidades". 
Outro autor de extrema importância na análise da conceituação de território e que nos legou contribuições importantíssimas é, sem sombra de dúvida, o Bacharel em Direito reconhecido como geógrafo, Milton Santos (1999). Apesar de o espaço geográfico permanecer como a categoria principal em sua análise, este autor também enaltece a concepção de "território usado", vislumbrando o uso e o controle social cristalizado no território. Sua ênfase é mais da via econômica, mas sinaliza, também, para o reconhecimento da política da cultura e da natureza como elementos constituintes do espaço e da configuração territorial. E nos afirma que:

O território não é apenas o conjunto dos sistemas naturais e de sistemas de coisas superpostas. O território tem que ser entendido como o território usado, não o território em si. O território usado é o chão mais a identidade. $\mathrm{A}$ identidade é o sentimento de pertencer àquilo que nos pertence. $\mathrm{O}$ território é o fundamento do trabalho, o lugar da residência, das trocas materiais e espirituais e do exercício da vida (SANTOS, 1999, p. 08).

Santos (1999, p. 07) expõe que o "território é o lugar em que desembocam todas as ações, todas as paixões, todos os poderes, todas as forças, todas as fraquezas, isto é, onde a história do homem plenamente ou parcialmente se realiza a partir das manifestações da sua existência". Isso pressupõe compreender o território para além dos aspectos estritamente "funcional" ligado a uma lógica político-econômica expressa nas relações de poder, pois, como já assinalado por Souza (2013), as relações de poder têm no espaço um componente indissociável tanto na realização de "funções" quanto na produção de "significados". E, diante das abordagens ora aqui apresentadas, assumimos as proposições defendidas por Milton Santos, para possibilitar entender os territóriosurbanos de sociabilidades gays da cidade de Salvador.

\section{Depoimentos, discursos e representações: a cidade de Salvador}

Fundada como São Salvador da Bahia de Todos os Santos, além da beleza arquitetônica, das suas festas populares, dentre elas, o maior carnaval do mundo, sua culinária impar de forte influência africana, a cidade de Salvador se destaca, "sobretudo, pelo seu passado histórico, por ter sido, desde 1549 até 1763, a primeira capital brasileira, assim como a segunda maior cidade do império português" (VASCONCELOS, 2016, p. 15) prestes a completar 470 anos em 29 de março de 2019, é um dos roteiros turísticos mais procurados em todo o país e também no exterior segundo dados da BAHIATURSA - Empresa de Turismo da Bahia S/A - BA ( 2018). 
Para Vasconcelos (2016):

Seu longo passado e sua riqueza durante o período colonial, quando se destacava como porto exportador de açúcar e de fumo e como porto de entrada de mercadorias europeias e de escravos africanos, resultaram numa combinação populacional que a tornou a maior cidade brasileira com população majoritariamente negro-mestiça (quatro quintos de sua população), além dos componentes de origem portuguesa e indígenas. (VASCONCELOS, 2016, p. 15).

É essa cidade, com características peculiares na sua formação sócio histórica, que também se destaca como um dos roteiros turísticos mais procurados pela população gay de vários lugares, além da comunidade gay local, elegendo alguns territórios da cidade como lugar preferido para o exercício de suas sociabilidades.

Para esta pesquisa, foi elaborada uma lista de alguns bairros da cidade com ocupação de espaços por sujeitos e práticas homossexuais. O Centro, principalmente no Pelourinho, Carlos Gomes, Avenida Sete, Campo Grande, Barris, Dois de Julho; a Barra, principalmente no Porto, Farol e Cristo, arredores da Avenida Oceânica; Rio Vermelho, especialmente o Largo da Mariquita, Largo de Santana, Praça Caramuru -antigo Mercado do Peixe - ver figura 1 .

Painel 1 - Ambientes popularmente conhecidos como espaços gays: Bairro Rio Vermelho em Salvador - BA, 2018.

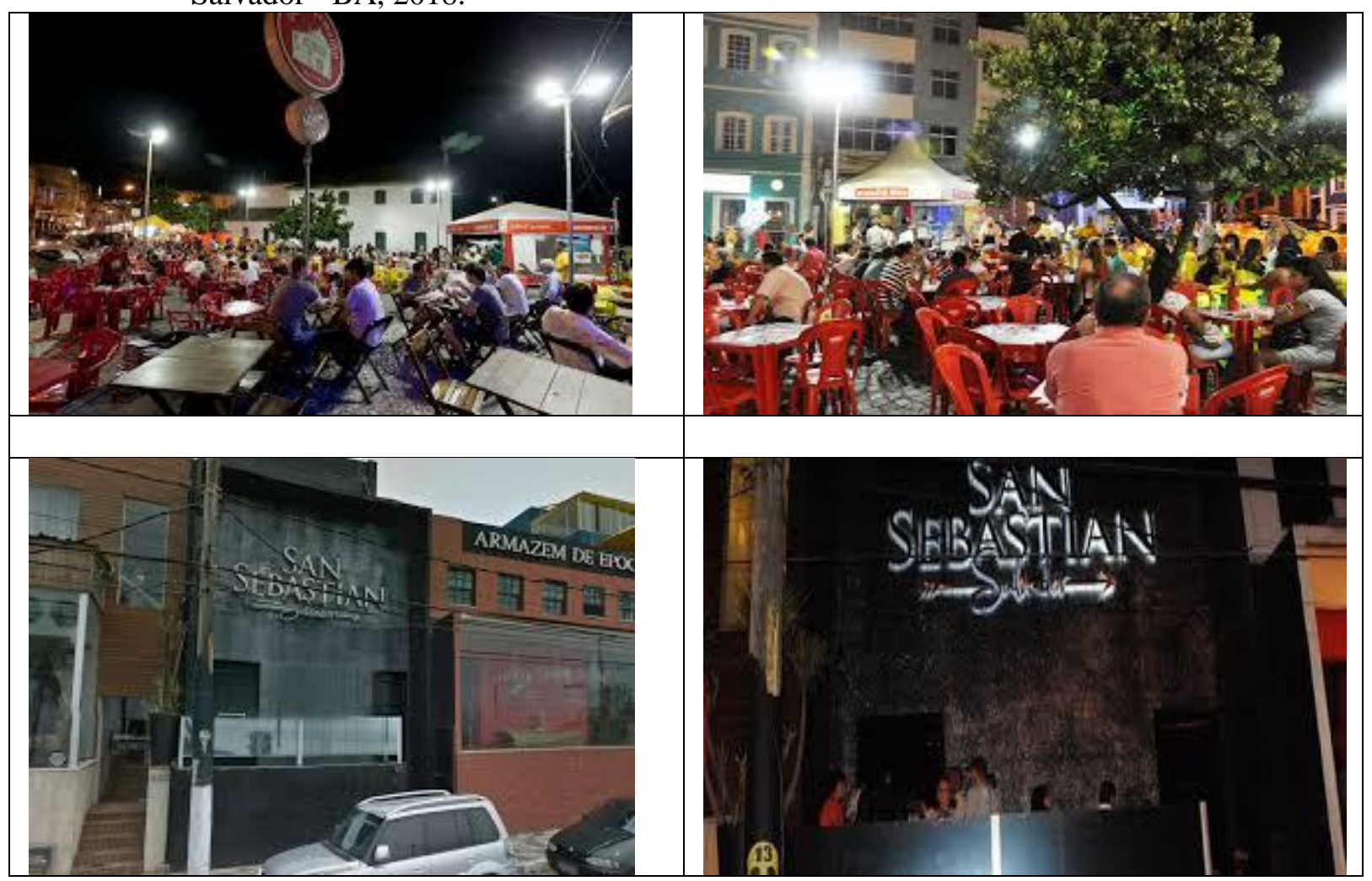

Fonte: Trabalho de campo, foto Celio Meira (2018)

GEOPAUTA, V. 2, n. 3, 2018 http://periodicos2.uesb.br/index.php/geo

Este é um artigo de acesso aberto sob a licença Creative Commons da CC BY 
Há outros espaços espalhados pela malha urbana de Salvador, especialmente em bairros mais afastados, que também são vistas como espaços de sociabilidades gays. Porém, nossos estudos foram realizados apenas nos bairros acima mencionados, por serem, segundo a população LGBTQI+ as áreas de maior concentração de serviços destinados a este público.

A partir de uma análise da concentração dos estabelecimentos e da distribuição dos espaços frequentados por homossexuais em Salvador, foi possível perceber uma utilização espargida, porém consolidada ao longo da cidade especialmente nos bairros acima supracitados. Vale ressaltar, que cada um destes espaços apresentam frequentadores gays diferentes quanto á condição socioeconômica, idade, interesses sexuais, etc. percebam isso nos depoimentos a seguir:

Não gosto de frequentar muito os espaços do centro da cidade. (Avenida Carlos Gomes, Avenida Sete), apesar de ser uma área histórica, porém, é muito perigosa. Muitos assaltos, e a gente ficam muito vulnerável a violência. Além do mais, tem muito michês se oferecendo para transar e acaba roubando a bicha, eu já fui assaltado lá algumas vezes quando saia de uma sauna que fica ali nas proximidades (Informação Verbal) ${ }^{4}$

Gosto muito de frequentar o Rio Vermelho, porque é de fácil acesso, tem transporte para lá toda hora, apesar da insegurança dos últimos meses por lá, mas inda é o melhor local, os bares são sofisticados, nos atende bem, as pessoas não nos olham atravessados, com preconceito, tem uma boate gay ali que a gente acaba amanhecendo o dia por lá. Tem gente bonita, você pode namorar à vontade sem medo de represália, as pessoas sabem que você é gay e pronto. (Informação Verbal) ${ }^{5}$

Nestes dois depoimentos, percebe-se uma preocupação com a segurança do público LGBTIQ+, o que acaba levando essas pessoas a procurarem lugares que ofereçam além de segurança conforto.

Nos bairros pesquisados, há espaços gays fechados e ao ar livre, sendo os primeiros mais frequentados pelo público gay que ainda não assumiu sua identidade para a família, amigos, colegas de trabalho, etc. já os segundos, são comumente frequentados por um público assumidamente gay. Também não podemos esquecer a preferência apontada pelas travestis por cinemas eróticos como base física para o exercício da prostituição, pois precisam de segurança para se prostituírem e os cinema - locais fechados - durante o dia servem para evitar o contato com um público maior e se proteger da violência. Estes cinemas de prostituição ficam nas imediações do Centro Histórico, especialmente na Rua Chile.

\footnotetext{
${ }^{4}$ Entrevista com frequentadores da noite de Salvador Marcos, 24 anos, Entrevista realizada por Celio Silva Meira em Janeiro de 2018 - Gravador de Voz - stereo marca Z680

${ }^{5}$ Entrevista com frequentadores da noite de Salvador Antônio, 30 anos, Entrevista realizada por Celio Silva Meira em Janeiro de 2018 - Gravador de Voz - stereo marca Z680
} 
O Bairro do Rio Vermelho, conhecido pelas festas, comemorações que acontecem, sobretudo depois do processo de requalificação, com mesas na calçada a outros que são quase clubes noturnos, de jazz ao vivo a karaokês, os bares gays dentro da comunidade homossexual de Salvador, é tido como um dos espaços de "fechação gay" . De segunda a domingo há opções para todos os gostos e bolsos. Neste bairro, possui toda uma programação voltada para esse tipo de público, como bares e restaurantes, boate que atende especialmente a este segmento. Com todos esses atributos, o supracitado espaço ficou super conhecido na "cena gay de Salvador". Porém é um espaço frequentado por um público gay de melhor poder aquisitivo, isso ficou evidenciado nas nossas entrevistas, vejamos:

Eu gosto muito de ir ao Rio Vermelho, porém, acho muito caro as coisas lá. É um bairro turístico, belíssimo, amo o Largo da Mariquita, o preço de uma cerveja lá, dá para comprar duas aqui no Centro, por isso, que prefiro ficar por aqui mesmo. Mas quando tem shows por lá eu vou sim. (Informação Verbal $)^{7}$

O bom aqui do Rio Vermelho é a boemia, as pessoas são bonitas, é um bairro bastante arejado, diferente dos espaços gays lá do Centro, são estruturas velhas, mal conservadas, não oferece nenhuma infraestrutura adequada. Além, é claro, de assaltos e assassinatos. (Informação Verbal).

O que ficou evidenciado nas entrevistas, é que há uma estratificação social muito clara dentro do mundo gay e para com o mundo gay. Segundo alguns depoentes, os espaços dedicados à oferta de serviços no Centro da cidade, não treinam seus funcionários suficientemente para lidar com a diversidade, diferentemente dos demais bairros, como Barra e Rio Vermelho por exemplo. Veja:

Aqui pelo centro da cidade, os gays vêm mesmo para procurar sexo em saunas, banheiros públicos, cinemões, praças, becos, já em outros lugares, vão para namorar, paquerar, azarar. No Centro é tudo mais escondido, fechado em ambientes. Ninguém fala que vem pra cá, não assume, gosta mesmo de falar que vai para os ambientes dos bairros da Barra, lá pelo Rio Vermelho, que o lugar das bichas bicudas, das finas. Lá os funcionários dos bares, boates tratam a gente com mais respeito, o poder aquisitivo fala mais alto, são obrigados a nos tratar bem, as bichas que lá frequentam têm dinheiro. (Informação Verbal) ${ }^{9}$

\footnotetext{
${ }^{6}$ No universo gay, espaços de fechação, são lugares onde os gays podem ficar a vontade, sem se preocupar com qualquer tipo de discriminação, preconceito.

${ }^{7}$ Entrevista com frequentadores do Rio Vermelho em Salvador- Diego, 22 anos, Entrevista realizada por Celio Silva Meira em Janeiro de 2018 - Gravador de Voz - stereo marca Z680

${ }^{8}$ Entrevista com frequentadores do Rio Vermelho em Salvador- Manuel, 45 anos, Entrevista realizada por Celio Silva Meira em Janeiro de 2018 - Gravador de Voz - stereo marca Z680

${ }^{9}$ Entrevista com frequentadores do Rio Vermelho em Salvador- Tarcísio, 34 anos, Entrevista realizada por Celio Silva Meira em Janeiro de 2018 - Gravador de Voz - stereo marca Z680
} 
Estes espaços devidamente destinados a uma convivência gay têm nos últimos anos merecidos estudos de diversos pesquisadores, dentre eles em nível de Estado da Bahia e em especial a cidade de Salvador podemos citar o estudo do antropólogo Luiz Mott, quem publicou uma pesquisa na qual mapeava a extensão da "cena gay" em Salvador no final dos anos 1990 e oferecia subsídios para a prevenção da AIDS. Em sua obra, Mott (2000, p. 13) definiu a "cena gay" como sendo "os espaços ao ar livre, logradouros urbanos e estabelecimentos comerciais que servemde nicho ecológico para sociabilização e encontros de variados graus entre homens com atração homossexual" e define:

[...] trata-se do conjunto de locais de encontros de homossexuais masculinos. Como o ponto principal do trabalho citado era mapear as áreas e oferecer o suporte para trabalhos de prevenção à AIDS, não há problema na utilização do conceito, desde que feita a ressalva de que é uma apropriação política de um conceito histórico e amplamente difundido (MOTT, 2000, p. 75).

A partir deste estudo do Antropólogo, pode-se se concretizar território de socialibilidades gays na capital baiana, dando foco às atividades nortunas de lazer. Após viabilizar o mapeamento destes territórios gays soteropolitano.

\section{Palavras conclusivas:}

No decurso deste trabalho, analisamos questões acerca da formação da territorialidade a partir de determinadas identidades, de um determinado grupo. Vimos que as minorias sexuais, além da busca de um campo simbólico que os façam ser reconhecidos por seus semelhantes, em muitos casos procuram nos territórios de convivência uma proteção, pelo medo do preconceito, da abjeção, fazendo com que o território definido por essas identidades seja não só um local de convivência, mas também um espaço de fuga, um refúgio, onde o indivíduo poderá exercer sua sexualidade de forma plena, sem ser repreendido, objurgado.

Em Buarque (1978), na canção ja assinalada neste texto, nos leva a refletirmos como a sociedade normativa nos joga pedras a todo instante, tanta nos enquadrarmos em seus modelos, nos diz cotidianamente que fomos feitos pra apanhar e que somos uma maldição social, uma anomalia, por isso, precisamos ser extintos, a higienização social.

Destarte, desejamos com esse trabalho, ora aqui apresentado, deixar uma reflexão sobre esse mote, destacando os preconceitos que perpassam a sociedade, revendo posturas, para que cada vez mais possamos pensar numa sociedade igualitária, onde todas as 
identidades sejam respeitadas, e onde os territórios como os de convivência homossexual não sirvam mais como um abrigo, como esconderijo, mas como um local de convivência pacífica, onde todos circulem sem medo do diferente, e principalmente, que essa diferença seja respeitada também fora desses territórios, não havendo mais restrições, nem discriminações.

A inclusão social implica democratização dos espaços sociais, a crença na diversidade como valor. Incluir não é apenas colocar junto, e, principalmente, não é negar a diferença, mas respeitá-la como distintiva do humano. Se em aparência a afirmação das diferenças se apresenta de forma antiética e discriminatória, por outro lado ela pode auxiliar na sensibilização dos sujeitos sociais quanto à aceitação das diferenças como premissa básica na criação de vínculos e laços sociais, o que poderia amenizar a exclusão, a intolerância e a injustiça.

\section{Referências}

ANGROSINO, Michael. Etnografia e observação participante. Porto Alegre: Artmed, 2009 (Coleção Pesquisa Qualitativa).

BUTLER, Judith. Problemas de gênero: feminismo e subversão da identidade. Trad. Renato Aguiar. Rio de Janeiro: Civilização Brasileira, 2017.

COLLING, Leandro. Mais visíveis e mais heteronormativos: a performatividade de gênero das pesonagens não-heterossexuais nas telenovelas da Rede Globo. In: COLLING. Leandro e THURLER, Djalma. Estudos e políticas do CUS- Grupo de Pesquisa Cultura e sexualidade. Salvador: EDUFBA, 2013. P.87-110.

EDUARDO, Márcio Freitas. Território, trabalho e poder: por uma Geografia relacional. Campo-Território, Rio de Janeiro, v. 1, n. 2, p. 173-195, 2006.

FERNANDES, Bernardo Mançano. Sobre tipologias de territórios. In: SAQUET, Marcos Aurélio; SPOSITO, Eliseu Savério (Org.). Território e territorialidades: teorias, processos e conflitos. 1. ed. São Paulo; Expressão Popular, 2009. p. 197-216.

FOUCAULT, M. História da sexualidade I: a vontade de saber. Rio de Janeiro: Edições Graal, 1988.

HAESBAERT, Rogério. O mito da desterritórialização: do fim dos territórios à multiterritorislidade. 1. ed. Rio de Janeiro, RJ: Bertand-Brasil, 2004.

HAESBAERT, Rogério; LIMONAD, Ester. O território em tempos de Globalização. etc..., espaço, tempo e crítica, Rio de Janeiro, v. 1, n. 2, p. 39-52, ago. 2007.

HALL, S. Da Diáspora. Identidades e Mediações Culturais. Belo Horizonte: Editora. UFMG, 2003.

HOLANDA, Chico Buarque. Geni e o Zepelim. Álbum: Opera Do Malandro. Rio de Janeiro, 1978. 
MISKOLCI, Richard. Teoria Queer: um aprendizado pelas diferenças. 2.ed.rev. e ampl. , $3^{\text {a }}$ reimp- Belo Horizonte: Autêntica Editora: UFOP, 2016. - (Série Cadernos da Diversidade; $6)$.

MONTENEGRO, Antonio Torres. História oral e memória: a cultura popular revisitada. São Paulo: Contexto, 2013.

MORAES, Antônio Carlos Robert de. Geografia: pequena história crítica. 16. ed. São Paulo: Hucitec, 1998.

MOTT, L. R. B. A Cena Gay em Salvador em Tempos de Aids. Salvador: Editora Grupo Gay da Bahia/Ministério da Saúde, 2000.

PRECIADO, PAUL B. Manifesto contrassexual. Tradução de Maria Paula Gurgel Ribeiro: São Paulo: n-01 edições, 2017.

RAFFESTIN, Claude. Por uma geografia do poder. São Paulo: Ática, 1993.

RATZEL, Friedrich. Ratzel. Tradução Antônio Carlos Robert de Moraes. 1. ed. São Paulo: Ática, 1990.

SÁEZ, Javier; CARRASCOSA, Sejo. Pelo cu: políticas anais (tradução de Rafael Leopoldo), Belo Horizonte, MG: Letramento, 2016.

SANTOS, Milton. O dinheiro e o território. GEOgraphia, Rio de Janeiro, ano 1. n. 1,p. 7-13, 1999.

SAQUET, Marcos Aurélio. As diferentes abordagens do território e a apreensão do movimento e da (i)materialidade. Geosul, Florianópolis, v. 22, n. 43, p. 55-76, jan./jun. 2007.

SAQUET, Marcos Aurélio. Abordagens e concepções de território. 2. ed. São Paulo: Expressão Popular, 2010.

SOUZA, Marcelo Lopes de. Os conceitos fundamentais da pesquisa sócio-espacial. 1. ed. Rio de Janeiro: Bertrand Brasil, 2013.

SOUZA, Marcelo Lopes. O território: sobre espaço e poder, autonomia e desenvolvimento. In CASTRO, Iná Elias et al. Geografia: conceitos e temas. 3. ed. Rio de Janeiro: Bertrand Brasil, 2001. p. 77-116.

SPOSITO, Maria Encarnação Beltrão. Introdução. In: SAQUET, Marcos Aurélio; SPOSITO, Eliseu Savério (Org.). Território e territorialidades: teorias, processos e conflitos. 1. ed. São Paulo: Expressão Popular, 2009.

VASCONCELOS, Pedro de Almeida. Salvador: transformações e permanências (15491999)- $2^{a}$. Ed. rev.ampl.-Salvador: EDUFBA, 2016. 